\title{
Is low dose Tranexamic acid less effective than a standard dose at reducing blood loss and inhibiting hyperfibrinolysis in hemorrhagic caesarean section? Multicenter double-blind placebo-controlled dose-ranging (TRACES) trial.
}

Anne-Sophie Ducloy-Bouthors ${ }^{1}$, Sixtine Gilliot ${ }^{2}$, Maeva Kyheng ${ }^{3}$, David Faraoni ${ }^{4}$, Alexandre Turbelin ${ }^{1}$, Hawa Keita ${ }^{5}$, Agnes Rigouzzo ${ }^{5}$, Gabirela Moyanotidou ${ }^{5}$, Benjamin Constant $^{6}$, Francoise Broisin ${ }^{7}$, Agnes Le-Gouez ${ }^{8}$, Remi Favier ${ }^{5}$, Edith Peynaud ${ }^{5}$, louise Ghesquiere $^{9}$, Gilles Lebuffe ${ }^{2}$, Alain Duhamel ${ }^{10}$, Delphine Allorge ${ }^{1}$, Sophie Susen ${ }^{1}$, Benjamin Hennart ${ }^{1}$, Emmanuelle Jeanpierre ${ }^{1}$, and Pascal Odou ${ }^{2}$

${ }^{1}$ Centre Hospitalier Regional Universitaire de Lille

${ }^{2}$ Université Lille 2 Droit et Santé

${ }^{3}$ Affiliation not available

${ }^{4}$ Baylor College of Medicine, Texas Children's Hospital

${ }^{5}$ Assistance Publique - Hopitaux de Paris

${ }^{6}$ Hopital de Seclin

${ }^{7}$ Hopital de la Croix-Rousse

${ }^{8}$ Hospital Antoine-Beclere

${ }^{9} \mathrm{CHU}$ Lille Jeanne de Flandre

${ }^{10}$ Universite Lille Nord de France

November 2, 2021

\begin{abstract}
Objective: To study the effect of a low $(0.5 \mathrm{~g})$ or a standard $(1 \mathrm{~g})$ tranexamic acid (TA) dose compared to placebo on clinical and biological endpoints in women experiencing postpartum hemorrhage (PPH) Design: TRACES trial is a double-blind, randomized, placebo-controlled, dose-ranging study Setting: 8 women hospitals in France. Population: Women experiencing $\mathrm{PPH}>800 \mathrm{~mL}$ during caesarean section. Method: After informed consent, patients were randomized to receive either TA $0.5 \mathrm{~g}$ $(\mathrm{n}=57)$, TA $1 \mathrm{~g}(\mathrm{n}=58)$, or a placebo $(\mathrm{n}=60)$. Data were collected at 8 time-points. Main outcome measures: Efficacy: additional blood loss after study drug, maternal morbidity, safety, biology: D-dimers, plasmin-antiplasmin complexes (PAP), simultaneousgeneration-thrombin-plasmin-potential. Results: Compared to $1 \mathrm{~g}$ dose, $0.5 \mathrm{~g}$ TA was less effective to reduce additional blood loss (300 mL [95\% confidence interval (95\%CI) 68 to 630] vs $134 \mathrm{~mL}$ [95\%CI50 to 419] ( $\mathrm{p}=0.042)$ ). Compared to placebo, $1 \mathrm{~g}$ TA, but not $0.5 \mathrm{~g}$, inhibited hyperfibrinolysis as shown by plasmin generation potential, $\%$ increase in D-dimers from injection to 120 minutes (93\% [95\%CI 68 to 118 ] vs $58 \%$ [ $95 \%$ CI 32 to 84 ] $(\mathrm{p}=0.06)$ vs $38 \%$ [95\% CI 13 to 63 ] ( $\mathrm{p}=0.003)$ and $\%$ increase in PAP from injection to 30 minutes (56\% [95\%CI 25 to 87] vs $13 \%$ [ 95\%CI 18 to 43] ( $\mathrm{p}=0,051)$ vs $-2 \%$ [95\%CI -32 to 28 ] $(\mathrm{p}=0.009))$. Conclusions: In this study, fibrinolysis inhibition was more sustained after the administration of $1 \mathrm{~g}$ TA compared to $0.5 \mathrm{~g}$ TA or a placebo. Further pharmacokinetic-pharmacodynamic modelling will be needed to determine the optimal TA dose to be administered in PPH. NCT 02797119
\end{abstract}

\section{Hosted file}


Draft_VF_30102021.docx available at https://authorea.com/users/355339/articles/543982-islow-dose-tranexamic-acid-less-effective-than-a-standard-dose-at-reducing-blood-loss-andinhibiting-hyperfibrinolysis-in-hemorrhagic-caesarean-section-multicenter-double-blindplacebo-controlled-dose-ranging-traces-trial

\section{Hosted file}

TAB_1_baseline_VF_30102021.docx available at https://authorea.com/users/355339/articles/ 543982-is-low-dose-tranexamic-acid-less-effective-than-a-standard-dose-at-reducingblood-loss-and-inhibiting-hyperfibrinolysis-in-hemorrhagic-caesarean-sectionmulticenter-double-blind-placebo-controlled-dose-ranging-traces-trial

\section{Hosted file}

Fig_1_Flowchart_VF_30102021.docx available at https://authorea.com/users/355339/ articles/543982-is-low-dose-tranexamic-acid-less-effective-than-a-standard-dose-atreducing-blood-loss-and-inhibiting-hyperfibrinolysis-in-hemorrhagic-caesarean-sectionmulticenter-double-blind-placebo-controlled-dose-ranging-traces-trial
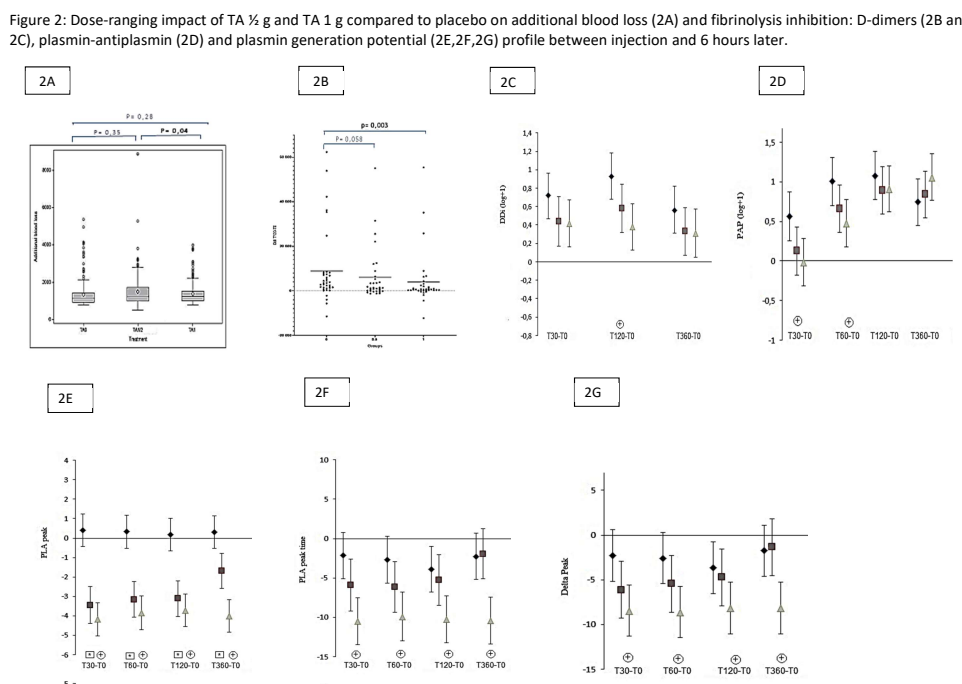

\section{Hosted file}

Table 2_TA_concentrations.docx available at https://authorea.com/users/355339/articles/ 543982-is-low-dose-tranexamic-acid-less-effective-than-a-standard-dose-at-reducingblood-loss-and-inhibiting-hyperfibrinolysis-in-hemorrhagic-caesarean-sectionmulticenter-double-blind-placebo-controlled-dose-ranging-traces-trial 